\title{
Research Paper \\ Explaining Post-Traumatic Growth: Thematic Synthesis of Qualitative Research
}

\author{
Zahra Asgari ${ }^{1}$ 이, ${ }^{*}$ Azam Naghavi ${ }^{2}$ 두
}

1. MA. in School Counseling, Department of Counseling, Faculty of Education and Psychology, University of Isfahan, Isfahan, Iran.

2. PhD. in Social Psychology, Assistant Professor, Department of Counseling, Faculty of Education and Psychology, University of Isfahan, Isfahan, Iran.

\begin{tabular}{|c|c|}
\hline $\begin{array}{l}\text { Use your device to scan } \\
\text { and read the article online }\end{array}$ & ditation Asgari Z, Naghavi A. Explaining Post-Traumatic Growth: Thematic Synthesis of Qualitative Research. Iranian Journal \\
\hline 口riniti & of Psychiatry and Clinical Psychology. 2019; 25(2):222-235. http://dx.doi.org/10.32598/ijpcp.25.2.222 \\
\hline 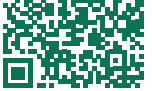 & doi http://dx.doi.org/10.32598/ijpcp.25.2.222 \\
\hline
\end{tabular}

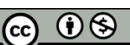

Received: 26 May 2018

Accepted: 30 Dec 2018

Available Online: $01 \mathrm{Jul} 2019$

Key words:

Psychological trauma Stressor related disorders, Human development, Qualitative research, Systematic review

\section{A B S T R A C T}

Objectives The present study aimed at employing a thematic synthesis approach to respond to this fundamental question: what is the post-traumatic growth process?

Methods The current study was a thematic synthesis of qualitative papers on post traumatic growth. From 50 Studies about post-traumatic growth from 2007 to 2018, 18 papers met the inclusion criteria for Systematic review. Papers were analyzed based on Thomas and Harden's thematic synthesis approach that includes three steps: free encoding of preliminary studies findings, organizing free codes into descriptive themes, and developing analytical topics using descriptive themes.

Results In total, after analyzing the results of the research, three main themes and 7 categories were obtained. The first theme was reaction to trauma with the category of primary emotions; the second theme was the requirements to begin the PTG with two categories including time and reality comprehension; and the third theme was the emergence of post-traumatic growth with four categories including Individual, social, psychological, and spiritual developments.

Conclusion According to the study findings it can be concluded that people show different emotions after expousure to traumatic events and after some time with processing the events they experience growth in different aspects of their lives.

\section{Extended Abstract}

\section{Introduction}

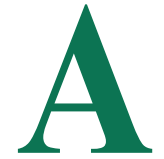

11 individuals are in the verge of encountering some kind of traumatic events at any given time. Traumatic event is sudden, unexpected, and far greater than an individual's coping capacity, and can create feelings of helplessness, fear, and confusion against the new life changes. Mental health issues including posttraumatic stress disorder, depression, anxiety disorders or psychosomatic symptoms are some of the consequences of facing with traumatic events. However according to recent studies, negative results are not the only consequences of experience of traumatic events and some people may experience growth and development after a sudden change in their life. Tedeschi and Calhon called these phenomena, Post-Traumatic Growth (PTG). PTG is defined as positive psychological changes after struggling with a traumatic life event and consists of five aspects: social relationship and developing social networks, new possibilities, pathways and opportunities, strengthening personal power, self-reliance, and changing inner spirituality and appreciation of

* Corresponding Author:

Azam Naghavi, PhD.

Address: Department of Counseling, Faculty of Education and Psychology, Isfahan University, Isfahan, Iran.

Tel: +98 (31) 37935516

E-mail: az.naghavi@edu.ui.ac.ir 
life. The main purpose of this paper was a thematic synthesis of qualitative papers about PTG and answering how the proper process of PTG for people experiencing a traumatic event is.

\section{Methods}

A thematic synthesis approach was employed to synthesize the results of qualitative studies about PTG. From 2007 to April 2018, there were 50 studies close to the current research question and 18 papers met the inclusion criteria. Based on Thomas and Harden's thematic synthesis approach there are three stages in synthesizing qualitative papers including free encoding of preliminary studies' findings, organizing free quotes into descriptive themes, and developing analytical topics using descriptive themes, and all 18 studies were analyzed based on these inductive approach.

\section{Results}

Three main themes were drawn from synthesizing qualitative paper findings including reaction to trauma, the requirements to begin the PTG, and the emergence of posttraumatic growth. Reaction to trauma consists of primary emotions. According to the data, primary emotions refer to a set of challenging emotions such as disappointment and hopelessness, guilt, regret, anger, fear, and shame. At the first exposure to trauma, people might experience the challenging emotions that can cause negative feelings leading to social exclusion, rumination, and an inclination to ending their lives. The second theme is the requirements to begin the PTG including time and reality comprehension categories. Understanding the reality of trauma is a breakthrough point for growth after traumatic events, and includes an ability to recognize trauma-related symptoms and differentiation of those symptoms from the self. The emergence of post-traumatic growth, another major theme, has four categories including personal development or strengthening personal power and modifying schema, social development including enhancement of social skills, restarting social activities, and altruism. Psychological development including acceptance of suffering, emotional maturity, appreciation of life , reappraisal and prioritization of values, goal setting, lifestyle improvement and spirituality development include discovering a meaning for life and spiritual strategies.

\section{Discussion}

Individuals facing traumatic events such as physical and life changing illnesses, bereavement or sexual abuse may experience post-traumatic growth after three stages including reaction to trauma, the requirements for the beginning of the PTG, and some developments (personal, social, psychological and spiritual) as a growth: According to the current study findings, it can be concluded that people show different emotions after exposure to traumatic events and after some time with processing the events they experience growth in different aspects of their lives.

\section{Ethical Considerations}

\section{Compliance with ethical guidelines}

There are no ethical considerations to be noted here.

\section{Funding}

This research did not receive any specific grant from funding agencies in the public, commercial, or not-forprofit sectors.

\section{Authors contributions}

Conceptualism, concepts, validation, Resources, writing, tracking, editing, and finalizing: All Authors; Research: Zahra Asgari.

\section{Conflicts of interest}

The authors declared no conflict of interests. 
This Page Intentionally Left Blank 


\title{
تبيين فرايند رشد يس از سانحه: تركيب مضمون مطالعات كيفى
}

\author{
زهرا عسكرى' هـ، "اعظم نقوى' هـ \\ 1- كارشناس ارشد مشاوره مدرسه، كروه مشاوره، دانشكده علوم تربيتى و روانشناسى، دانشكاه اصفهان، اصفهان، ايران.

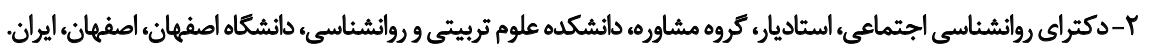

\begin{abstract}
حكبد
هـدافت هدف از مطالعه حاضر استفاده از روش تركيب مضمون براي مرور يُروهشهاى كيفى به منظور باسخ به اين سؤال اساسى بود كه فرايند

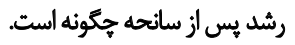

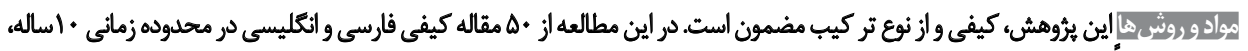

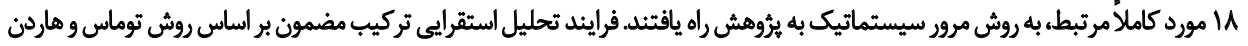

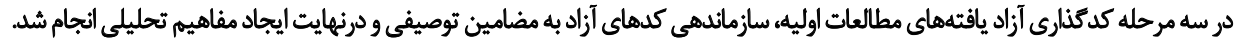

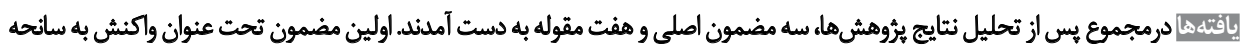

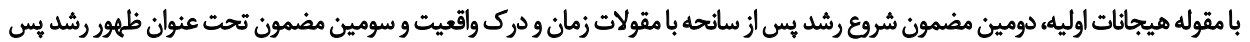

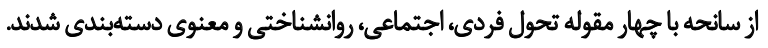

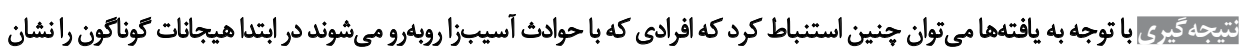

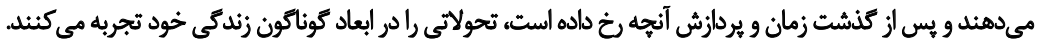

تاريخ دريافت: ه+خرداد

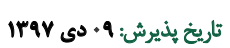

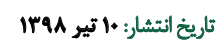

كليدوازٔهها: تروماى روانشناختي، اختالات مرثبط با استروس،

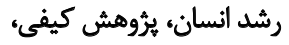
مرور سيستماتيك انسي تروش
بر اساس هُؤهشهاى تدسكى' و كالهون ' بديده رسيدن به

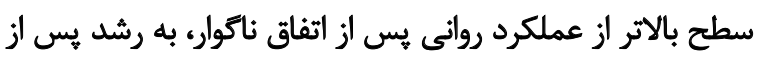

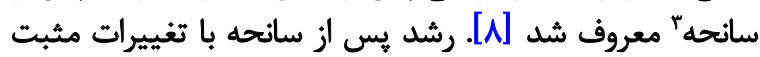

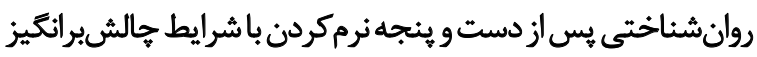

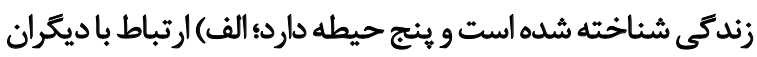

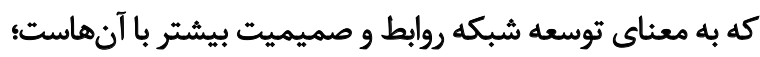

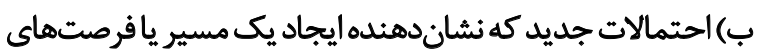

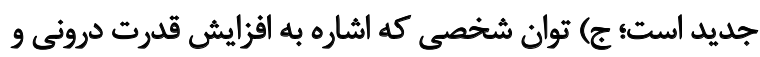

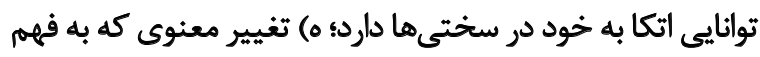

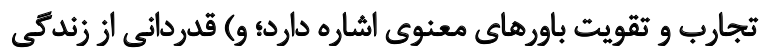

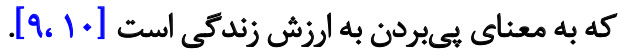

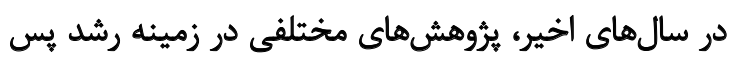

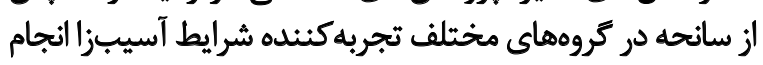

1. Tedeschi

2. Calhoun

3. Posttraumatic growth (PTG) dâे هرساله در سراسر جهان رويدادهاي آسيبزاه به مرك و نتايج

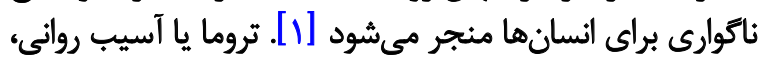

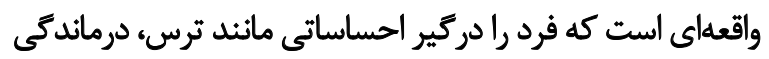

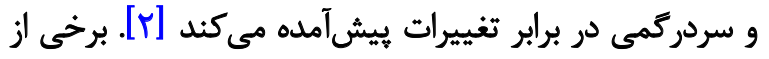

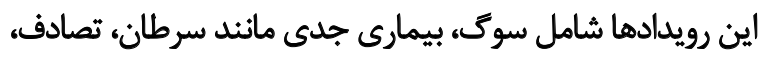

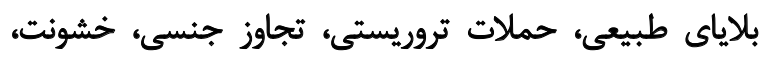

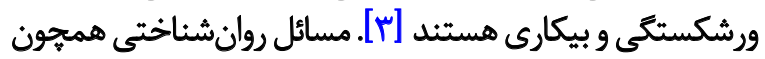

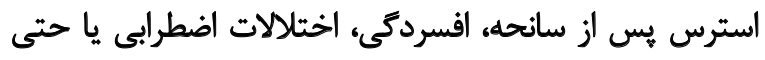

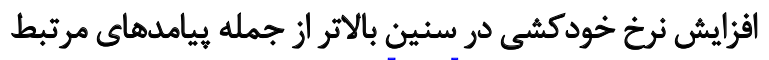

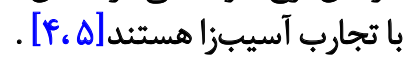

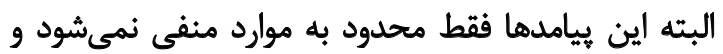

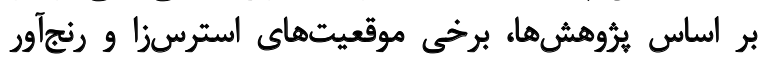

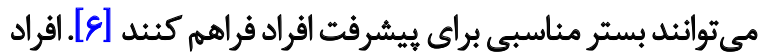

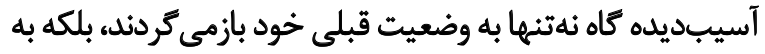

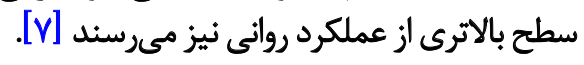

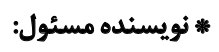
اعظم نقوى نشانى: اصفهان، دانشكاه اصفهان، دانشكده علوم تربيتى و روانشناسى، كروه مشاوره. تلفئ: تشائ: az.naghavi@edu.ui.ac.ir يست الكترونيكى 


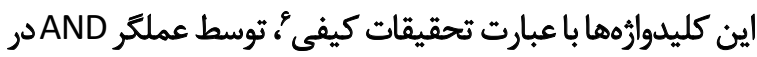

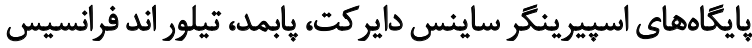

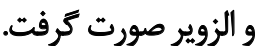

در مرحله غربالكرى دو نويسنده با همكارى همديكر تمام

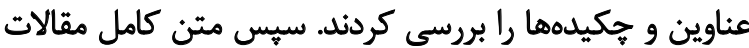

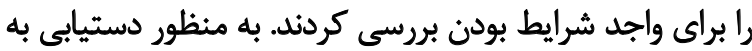

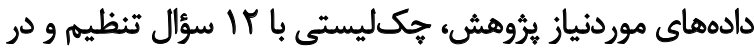

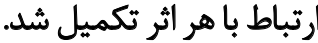

از آنجا كه معيارهاي ورود عبارت بودند از سانحه ويرُّى هاييى

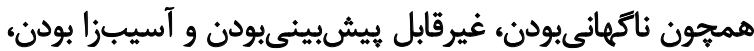

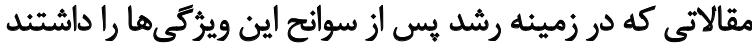

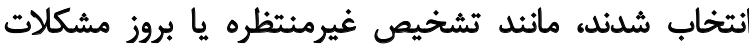

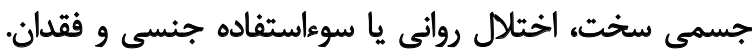

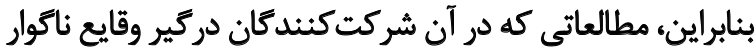

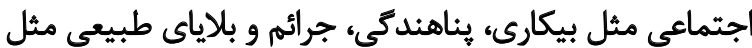

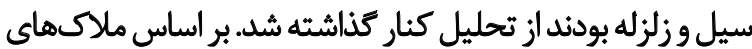

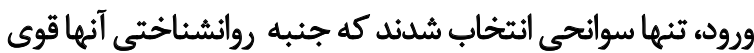

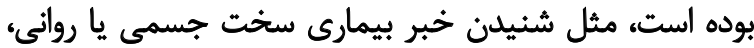

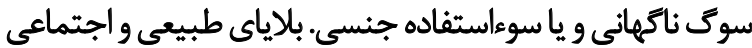

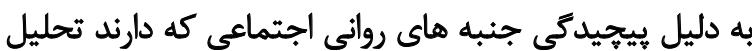

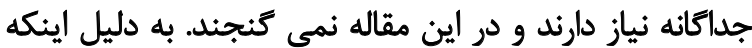

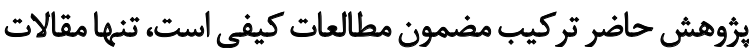

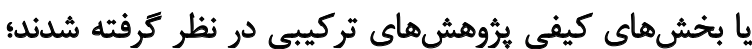

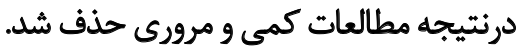

رشد يس از سانحه فقط از ديدكاه شخص آسيبديده مدنظر

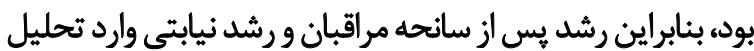

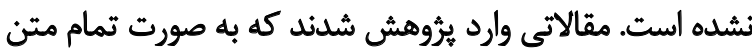

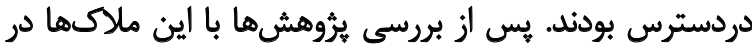

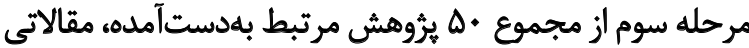

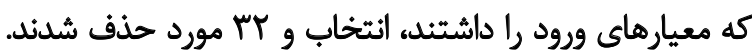

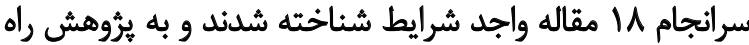

$$
\text { يافتند (تصوير شماره ()). }
$$

براي تحليل دادهها روش استقرايى تركيب مضمون توماس و

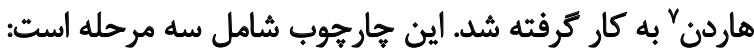
كدكذارى آزاد يافتههاى مطالعات أوليه

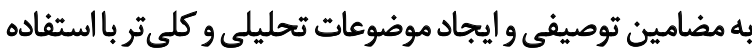

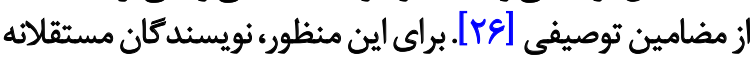

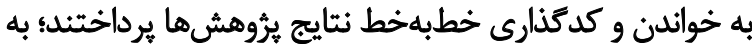

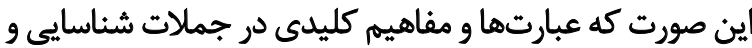

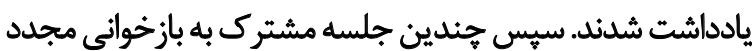

6. Qualitative research

7. Thomas \& Harden
شدهاست. در ميان آنها يُؤوهش هاي كيفى سهم مؤثرى در تبيين

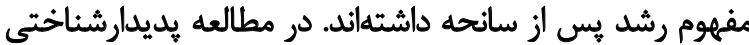

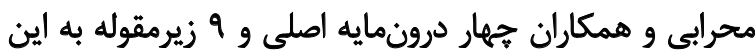

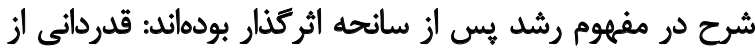

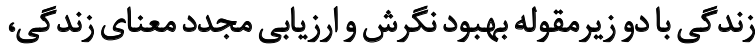

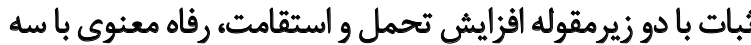

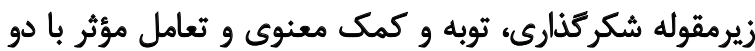

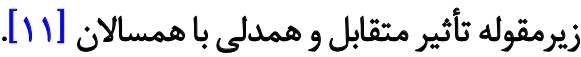
نتايج يُوهش فاضل و همكاران نيز نشان داد خودشكوفايى

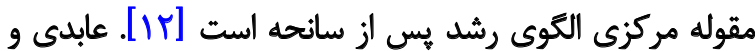

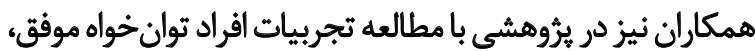

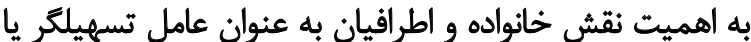

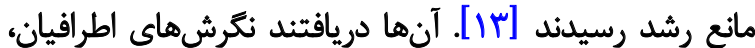

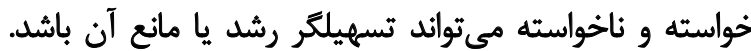

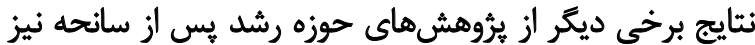

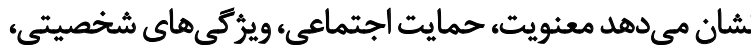

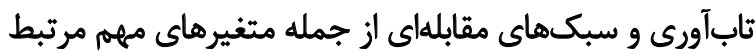

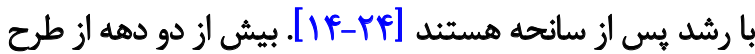

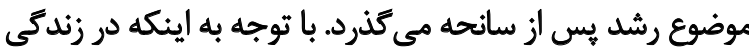

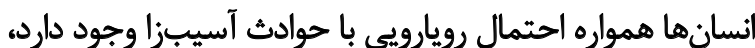

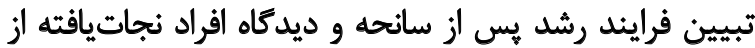

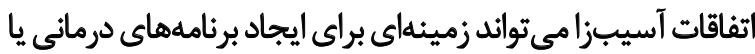

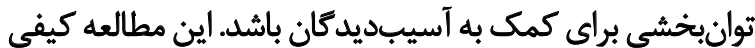

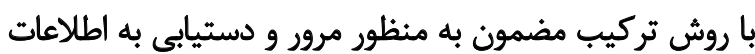

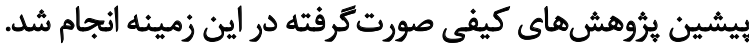

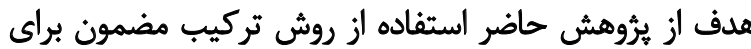

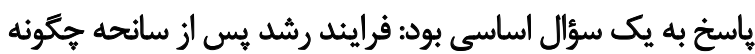
است؟ باسخ با

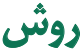

اين يُوهش با روش تركيب مضمون انجام شد كه يكى از

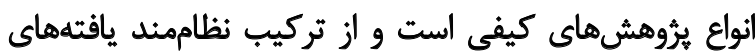

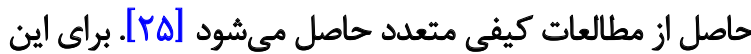

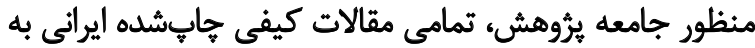

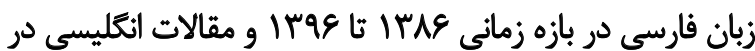

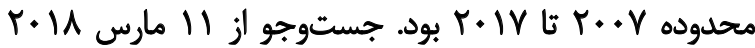

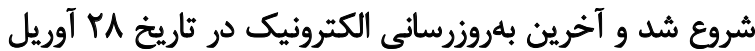

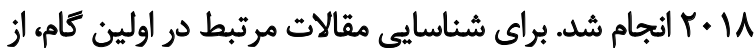

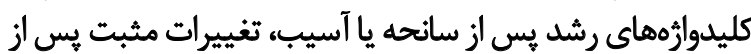

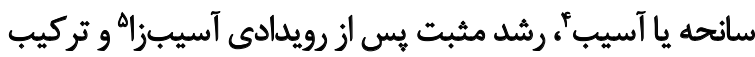

4. Positive changes after trauma

5. Positive growth after traumatic events 


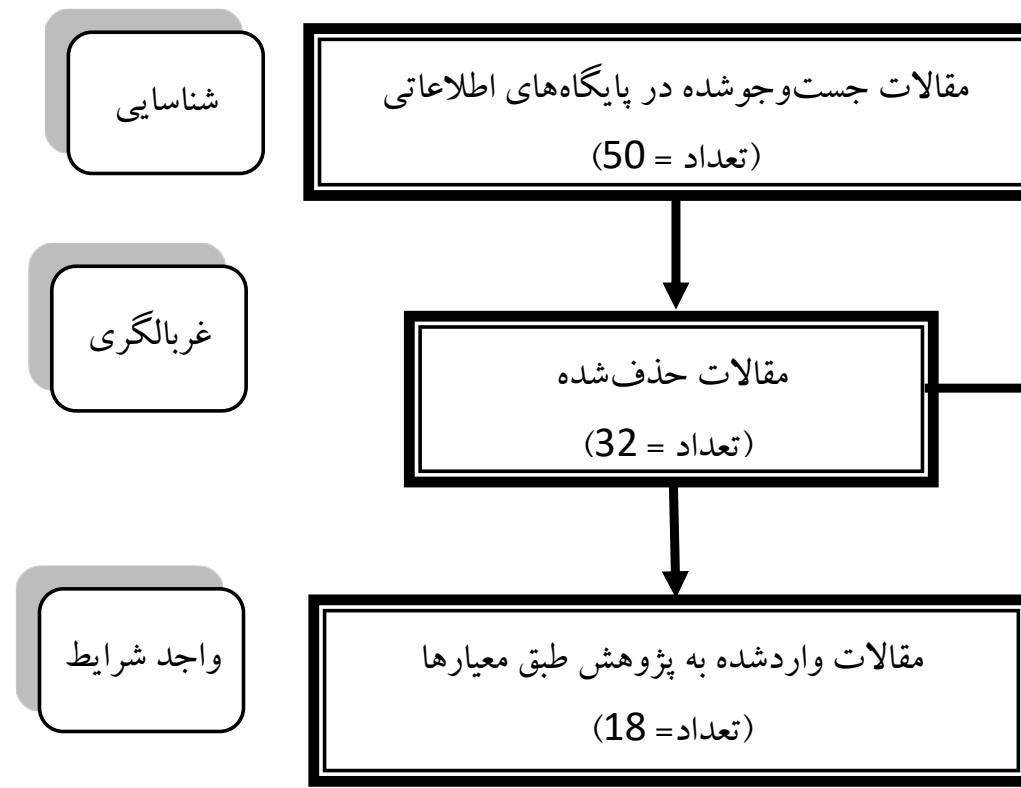

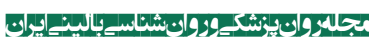

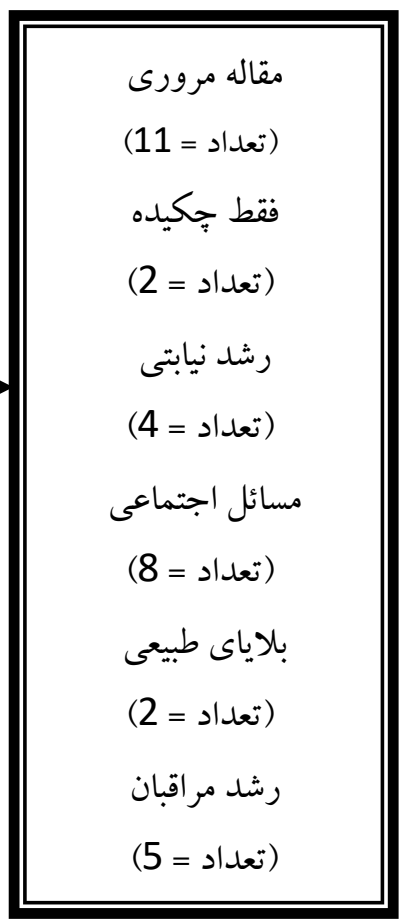

تصوير ا.دياكرام جستوجو و انتخاب مقالات

كدها براي نزديك كردن ذهن نويسندكان به برداشت مشترك از

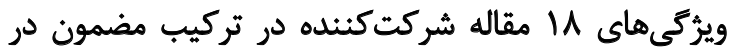

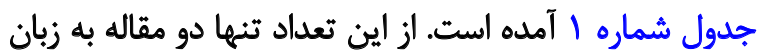

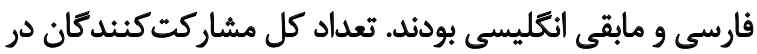

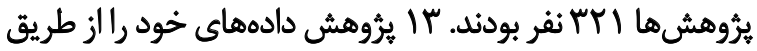

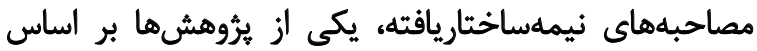

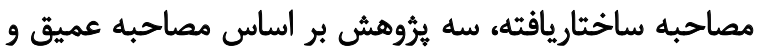

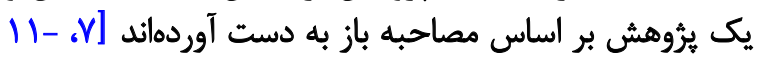

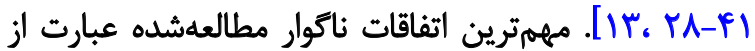

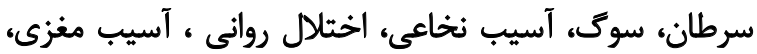

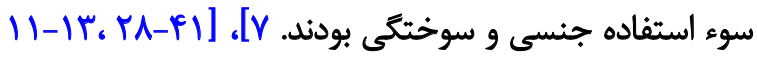

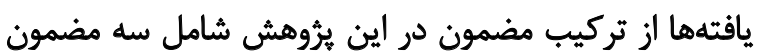

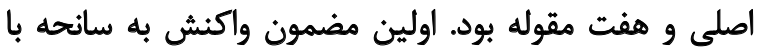

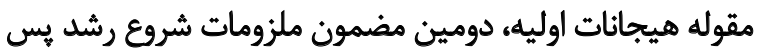

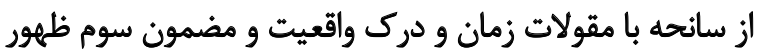

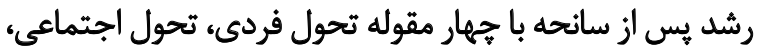

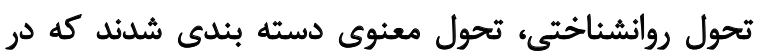

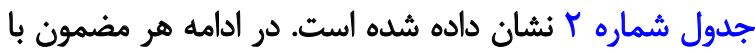
توجه به زيرمقولههاى آن ارائه مى آشود.

$$
\text { مضمون أول: واكثش به سانحه }
$$

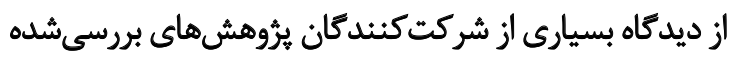

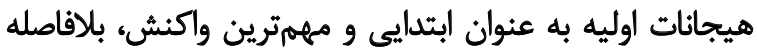

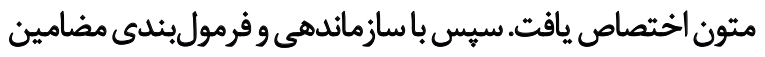

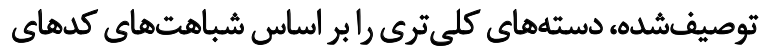

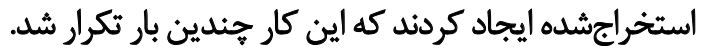

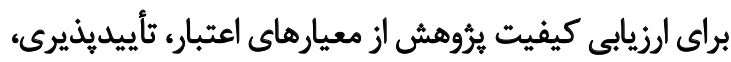

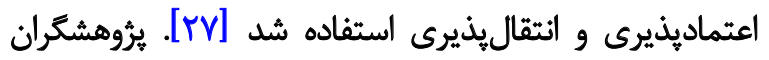

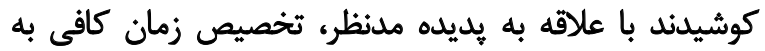

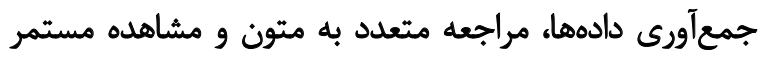

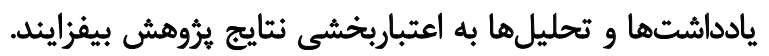

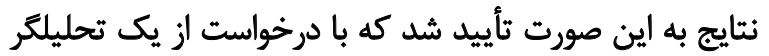

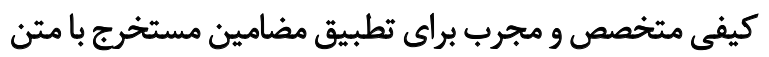

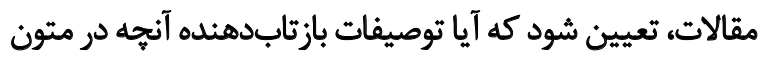

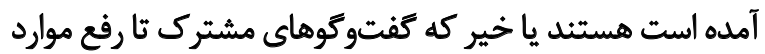

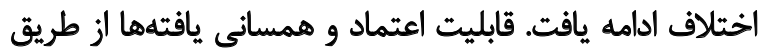

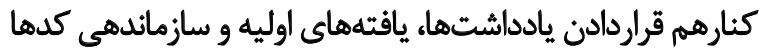

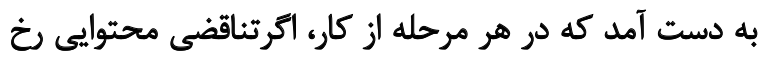

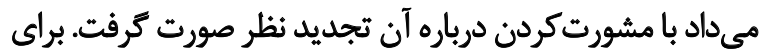

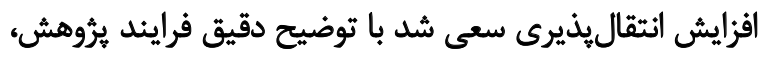

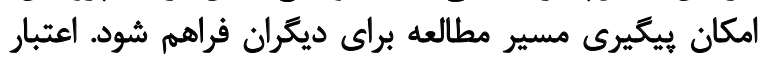

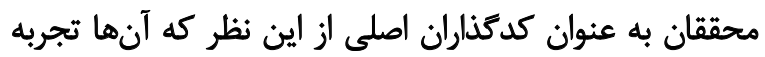

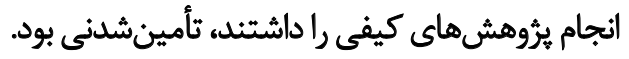


جدول ا. شبكه مضامين فرايند رشد يّ از سانحه

\begin{tabular}{|c|c|c|}
\hline زيرمقولهها & مقولهها & مضمون اصلى \\
\hline ثاميلى، كناه، خشه، يشيماني، ترس، شرم و درماندكى & هيجائات اوليه & واكنش به سانحهة \\
\hline- & مرى واقعيت & ملزومات شروع رشّد يس از سانحهي \\
\hline توان شخصى و اصلاح خوديثداره & تحول فردى & \\
\hline ارثقاى مهارتهاى اجتماعى، احياى فعاليتهاى اجتماعى، نوعدوستى & 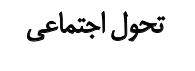 & ظهور رشد يس از سانحه \\
\hline 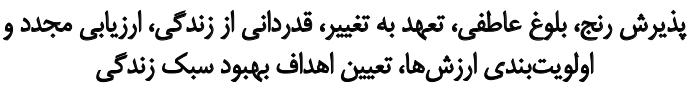 & تحول روانشناختمى & \\
\hline كشف هعناى زئدكى و راهبردهاى هعنوى & تحول معنوى & \\
\hline
\end{tabular}

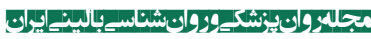

به تحولات مثبت و مطلوبى در نتيجه فراز و نشيبهاي هيس

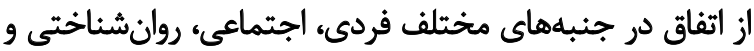
معنوى است.

\section{تحول فر في}

اكثر مطالعات بر تحول فردى تمركز داشتئد كه به معناي

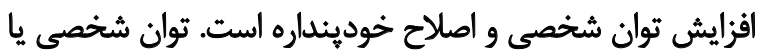
به عبارتى احساس قدرت درونى دربردارنده احساس استقان إنلال، اعتمادبه نفس، خودكارآمدى، خوش احبينى

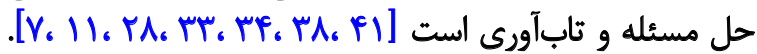

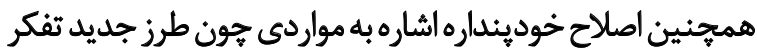

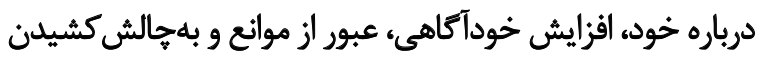

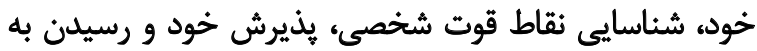

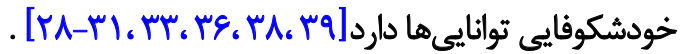

\section{تحولاجتماعى}

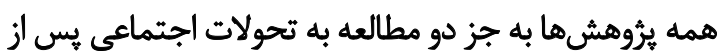

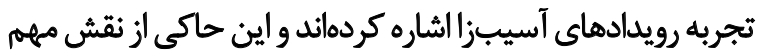

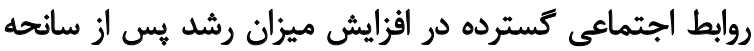

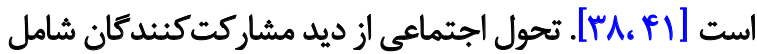

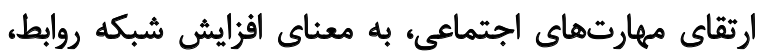

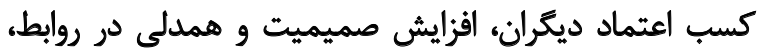

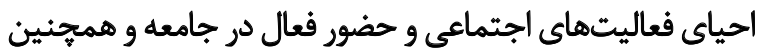

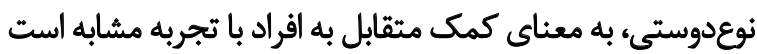
[V. II-Ir. YA-rV.r. Y. F.]

\section{تحول روان شيناختي}

در بسيارى از يُروهش ها به تغييرات روانشناختى اشاره شده
يس از رويارويى با سانحه آسيبزا ايجاد مي شوند. اين هيجانات

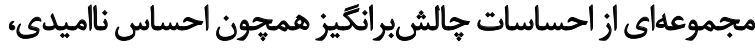

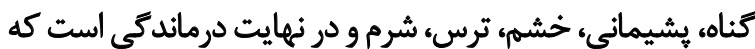

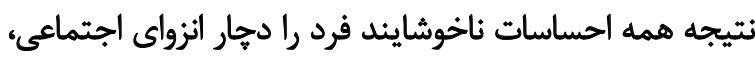

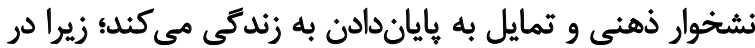

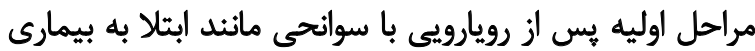

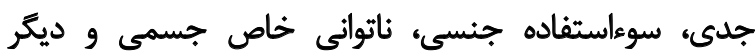

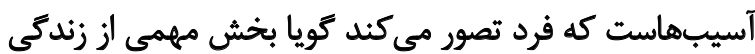

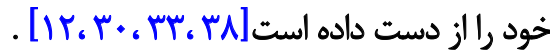

$$
\text { مضمون دوم: ملزومات شيروع رشد يس أز سانحه }
$$

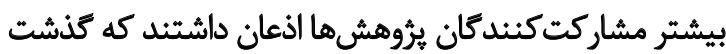

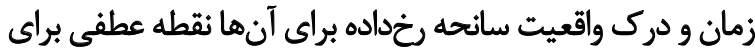

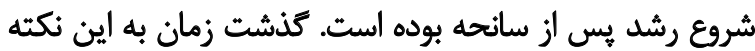

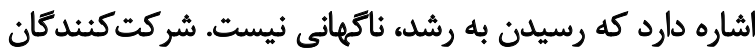

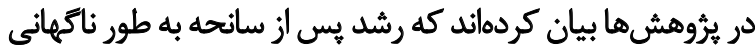

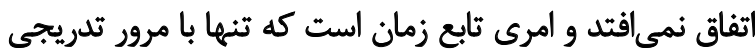

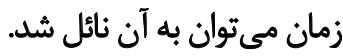

درك واقعيت شامل يردازش آنجه كه اثفاق افتاده است، تواناييى

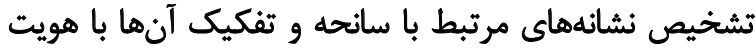

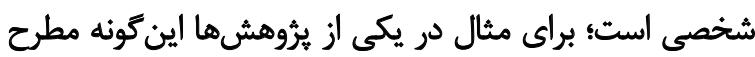

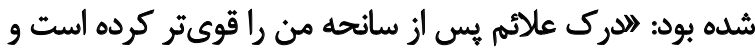

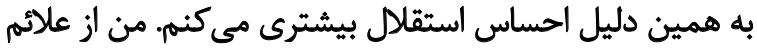

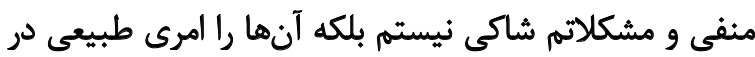

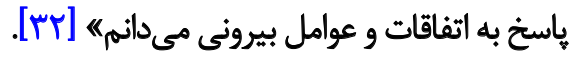

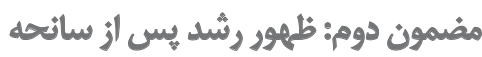

رشد يس از سانحه از ديد مشاركت كنيندكان به معناي دستيابي 
جدول r. مطالعات واردشده به يُروهش در زمينه رشد يَ ازّ سانحه

\begin{tabular}{|c|c|c|c|c|c|c|}
\hline خلاصه نتايج & تعمئرى و تعدى & جمع أورى & عنوان يُؤوهش & انتشار & نويسنده اول & شماره \\
\hline 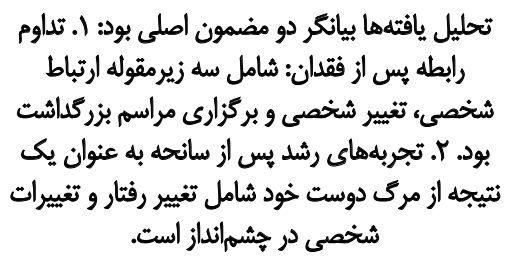 & 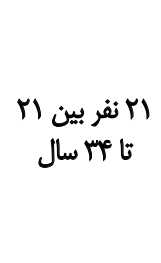 & نيمهساختاريافته & 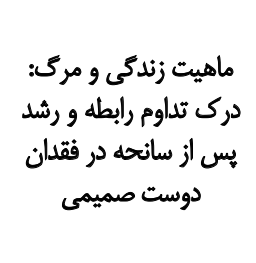 & $r+11$ & استين و همكاران & 1 \\
\hline 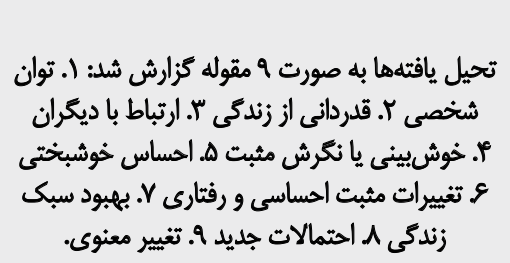 & 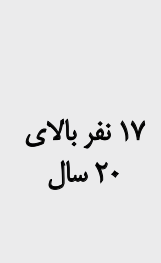 & نيمهساختاريبافته & 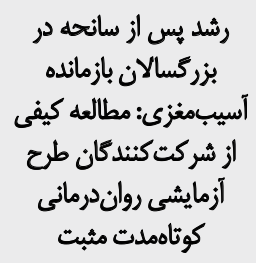 & $r \cdot 11$ & كمكاران [V] & $r$ \\
\hline
\end{tabular}

براى بازماندكان، سرطان تغييرى در زندكى بود و وانو

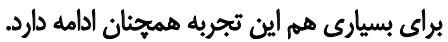

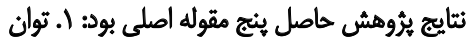

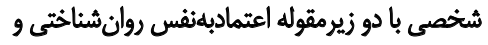

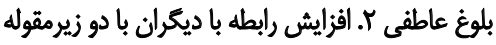

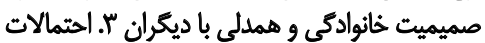

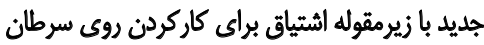

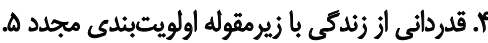

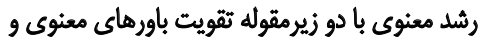
شركت در مراسم و فعاليتهاى مذهبيى. تحليل دادهاى كيفى بيانكر بنج مقوله اصلى است:

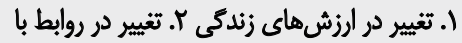

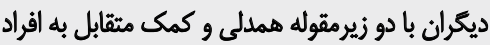

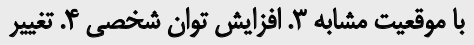

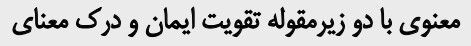

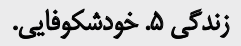

مشاركت كنندكان در مصاحبههاى خود نتايج مثبتى

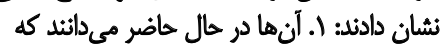

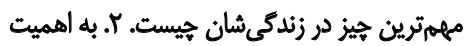

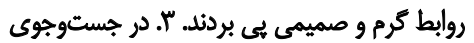
معنايع براى خودكشى اعضاى خانواده هستند.

سه مقوله اصلى و با زيرمقوله به دست آمده است:

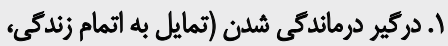

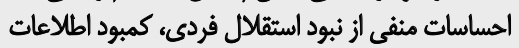

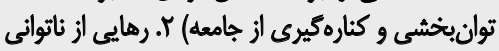

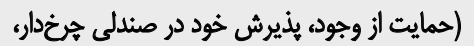

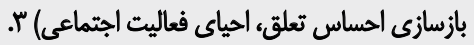

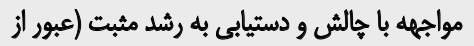

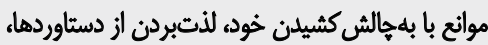
افزايش خرد، كمك به دوستان توانخ خواه).

\begin{tabular}{|c|c|c|c|c|}
\hline به نفر با & & وحشتناك بوده اما برونداد & & \\
\hline سابقه ابتلا به & هصاحبه & خوبى هم داشت: رشد & $Y \cdot I V$ & زأهوراو همكاران \\
\hline 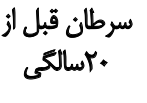 & نيمdساختاريافته & بزيس ازلان سانحه درم ميان & 101 & {$\left[{ }^{\prime}[]\right.$} \\
\hline
\end{tabular}

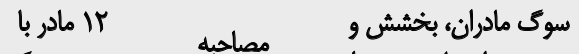

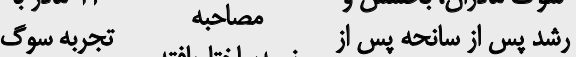 فقفلن يك كودى
r.iv م مارتين ككواو همكاران [بران




\begin{tabular}{|c|c|c|c|c|c|c|}
\hline خلاصه نتايج & تعدئَ ويزى & جمعآورى & عنوان يُؤوهش & انتشالر & نويسنده اول & شماره \\
\hline 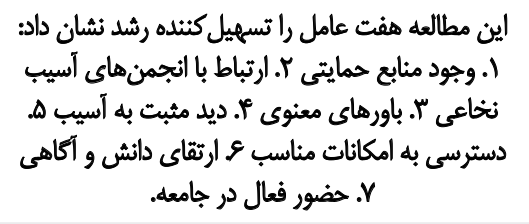 & مبثالا بيه أسيبي موفق & ثيمهناختاريافته & 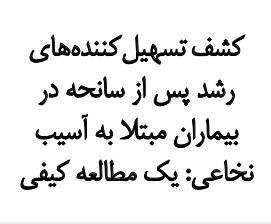 & $r \cdot I V$ & خانجانى و همكاران & $v$ \\
\hline 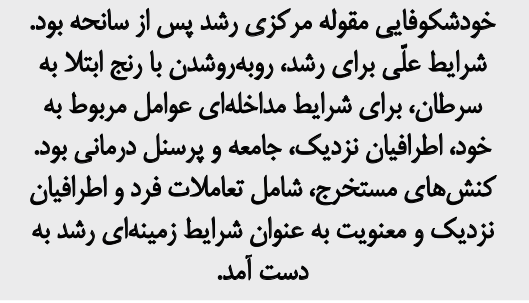 & به بـ بيمار مبتلان & نيمهساختارياقته & 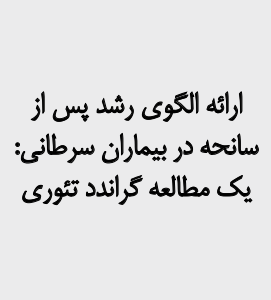 & Iras & فاضل و همكاران & 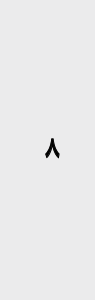 \\
\hline 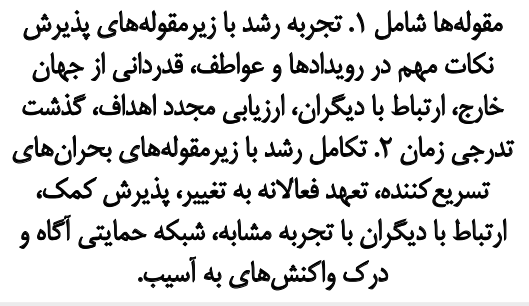 & 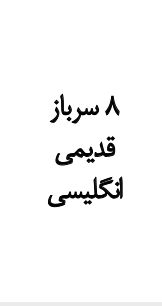 & ثيمهنساختاريافته & 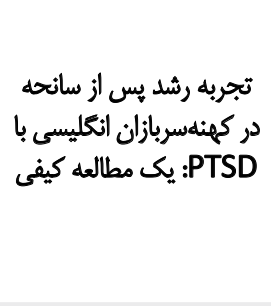 & $r+18$ & هالمر و همكاران [Tس] & 9 \\
\hline 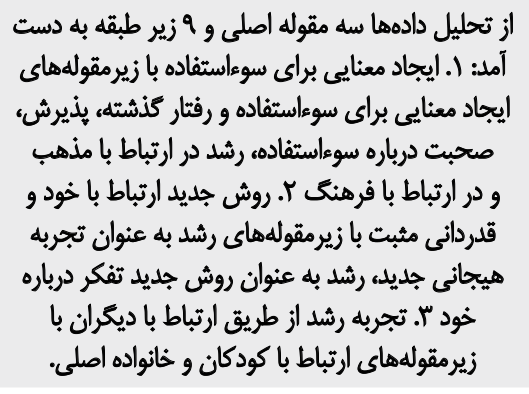 & 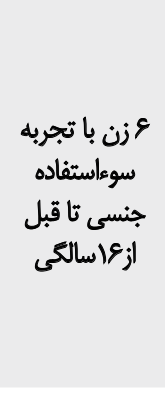 & نيمهن هصاخباريه & 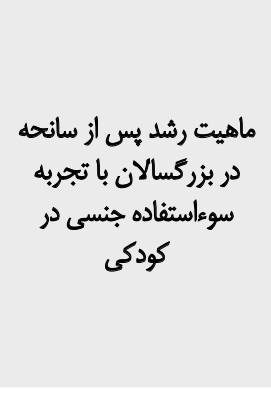 & $r \cdot 18$ & هارتلى و همكاران & 1. \\
\hline 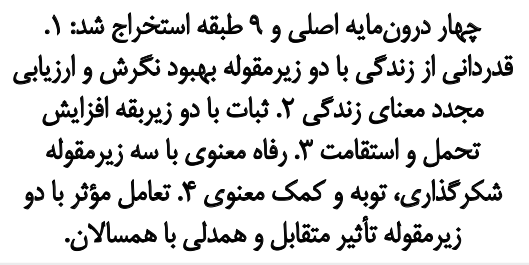 & 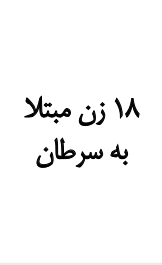 & نيمهساختاريافته & 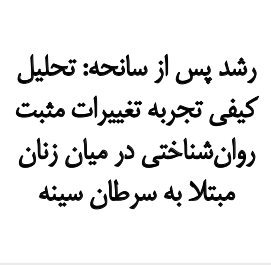 & $r \cdot 10$ & $\begin{array}{c}\text { هحرابي و همكاران } \\
\text { [111 }\end{array}$ & 11 \\
\hline 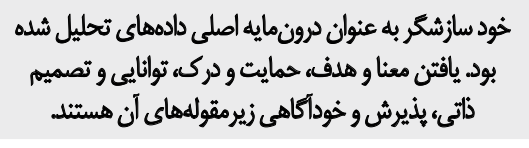 & 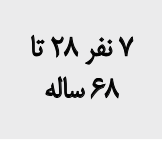 & نيمهساختارياقته & 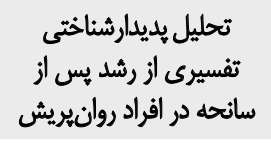 & $r+1 \Delta$ & ميلبك و همكاران & Ir \\
\hline 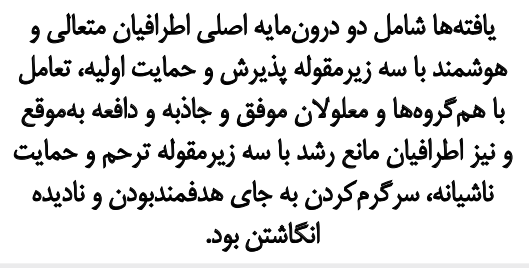 & 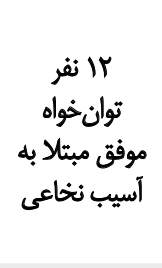 & هصاحبه عميق & ثأملى بر تجارب معلولان: & ז9 & 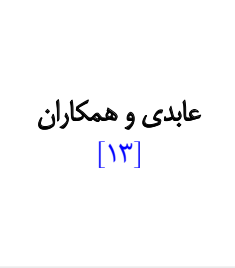 & Ir \\
\hline 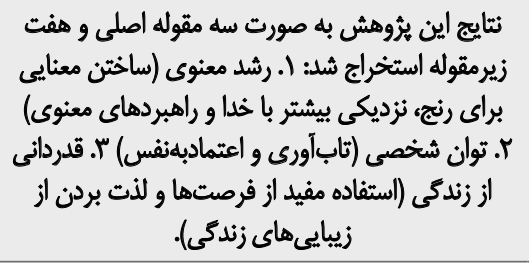 & 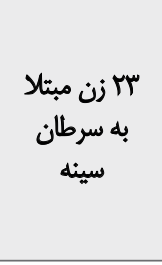 & مصاحبه باز & ييماران مبتلا به از سائحه درطان & $r+1 r$ & فلاح و همكاران [1 أ] & If \\
\hline
\end{tabular}




\begin{tabular}{|c|c|c|c|c|c|c|}
\hline خلاصه نتايج & تعداد ويزّى & جمعآورى & عنوان برؤوهش & اتثشار & نويسنده اول & شماره \\
\hline 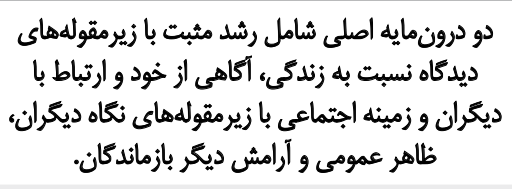 & ع انفر بالاى سال & ثيمهساختارياقته & 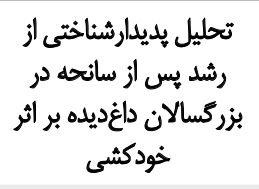 & $r+11$ & 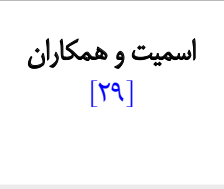 & 10 \\
\hline 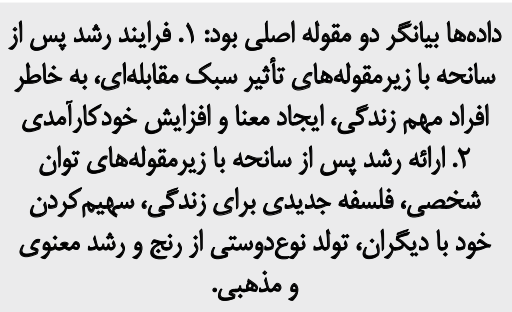 & 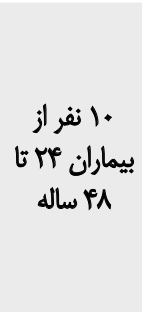 & نيمهساختاريافته & 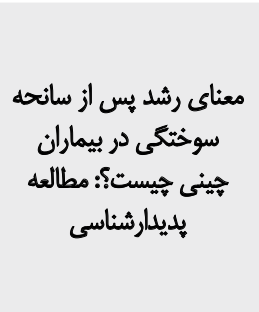 & $r+1$. & راى و همكاران [بر] & 18 \\
\hline 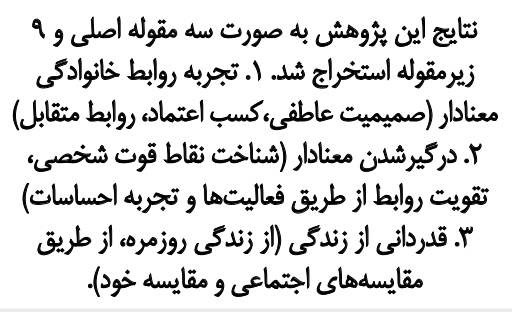 & 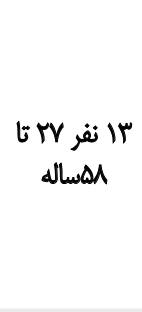 & مصاحبه عميق & تجراي افراد مبنا بلا به أز سائحيه & $r+r 1$ & هان و همكاران [جq] & iv \\
\hline 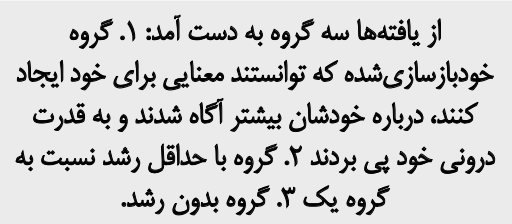 & كا مه ثفر & ساختاريافته & 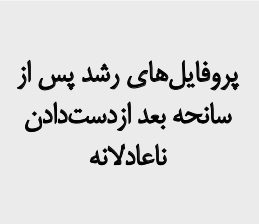 & $r . r r$ & 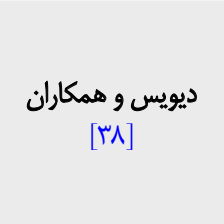 & M \\
\hline
\end{tabular}

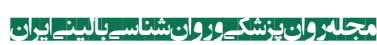

كزارش شده است و شامل كشف معناي زندكي و راهبردهاي

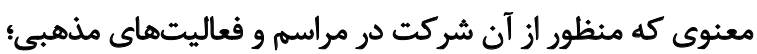

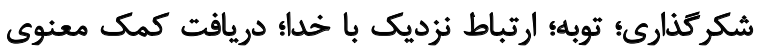

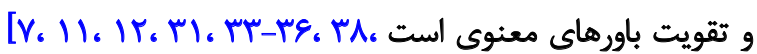

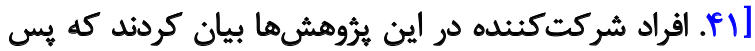

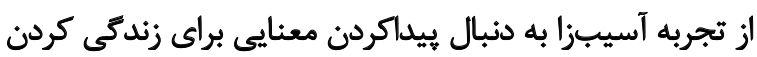

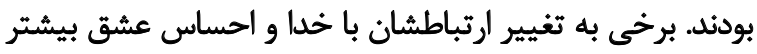

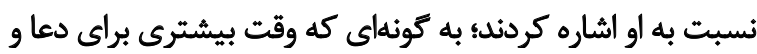

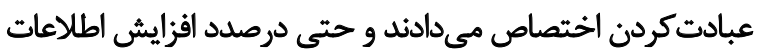
مذهبي خود هم بودند.

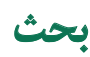

هدف از يثروهش حاضر ياسخ به اين سؤال اساسي بود كه فرايند

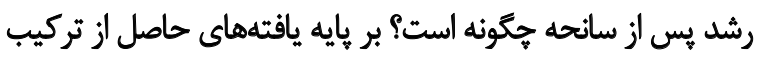

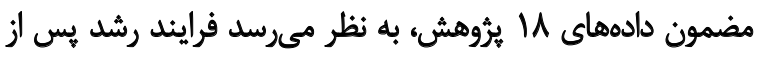

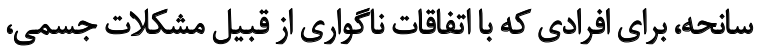

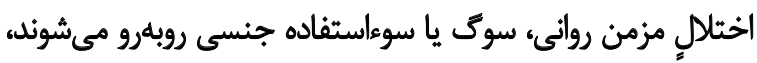

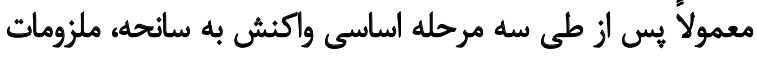
شروع رشد يس از سانحه و ظهور رشد يه إز از سانحه است.
است كه عبارت است أز يذيرش رنج؛ بلوغ عاطفي؛ به معناي ثجربه

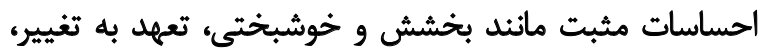

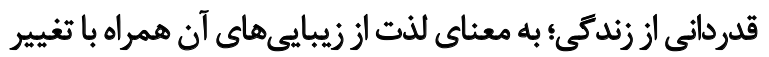

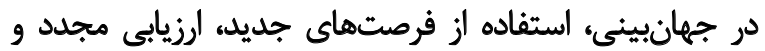

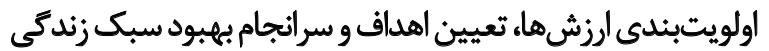

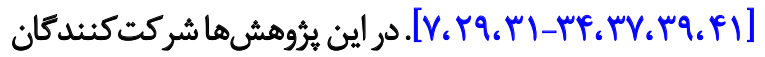
بيان كر داند كه رنج بخش جدايي نايذير زندكى انسان هاست. وقوع

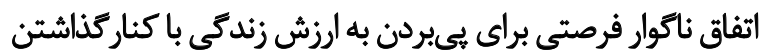

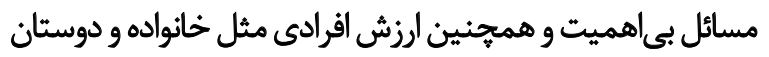

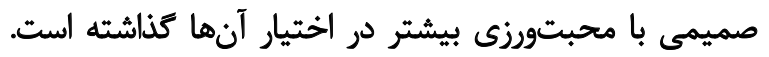
به همين دليل به تشخيص ارزشهاي واقعى زندكى خونى خود مثل

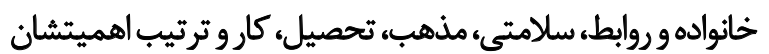

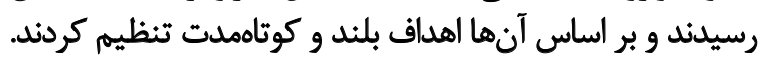
برخي به جستوجو ياساختن موقعيتهاي شُغلي جديد ير برداختيند

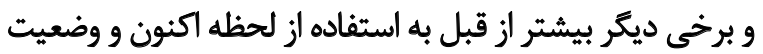
سلامتى خود مثل تغذيه، ورزش و خواب توجه كردهاند.

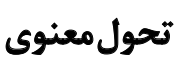

در بيشتر يثوهشه ها تحول معنوى به عنوان بُعدى بسيار مههم 
مهمى در تسريع روند رشد يس از سانحه ايفا كند. همانطور

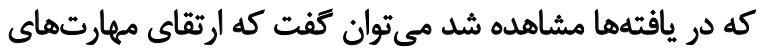

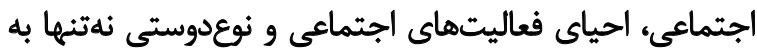

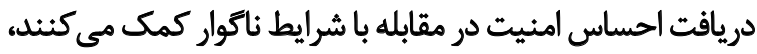

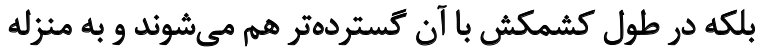

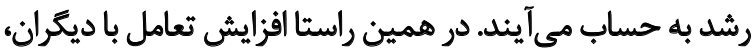

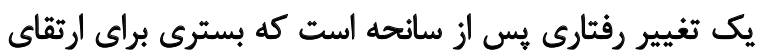

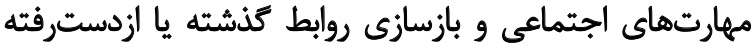
فراهم مي كند [TrV] به نظر بسيارى از شركتكنندكان يُؤهشها، تغيير در

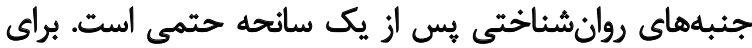

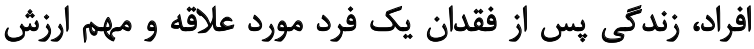

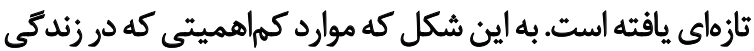

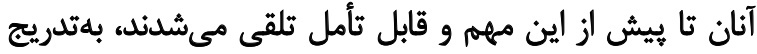

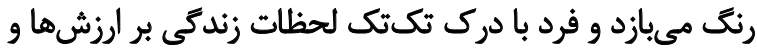

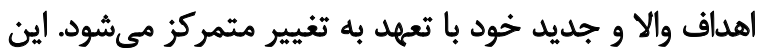

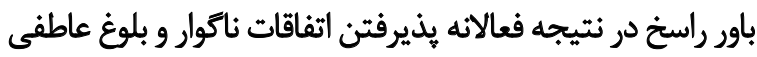

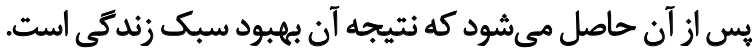

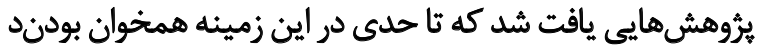

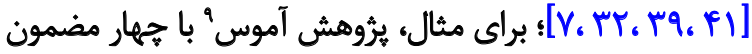

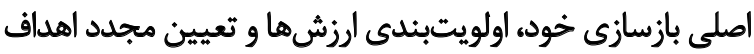

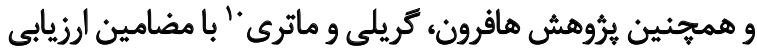

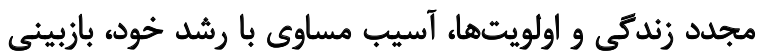

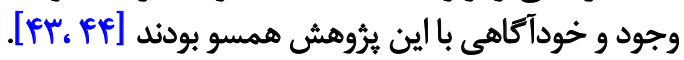

در بيشتر ديدكاهها، بعد اصلى رشد يس إز سانحه، تحول

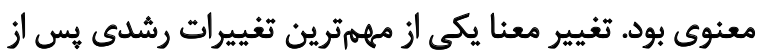

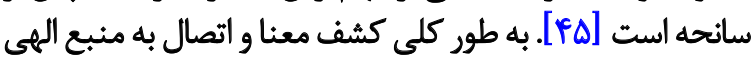

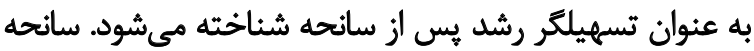

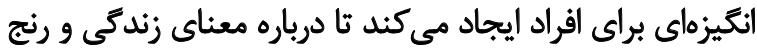

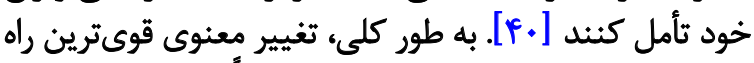

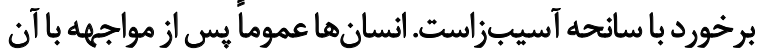

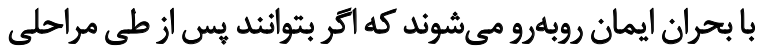

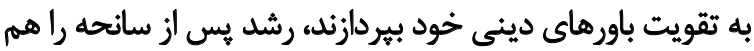

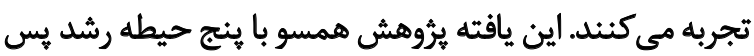
از سانحه از نظر تدسكى و كالهون بود [9].

\section{تيجيكَّيرى}

اين ثروهش اولين بروهش از نوع تركيب مضمون در زمينه

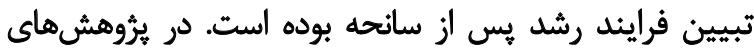

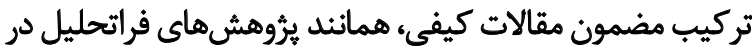

9. Amos

10. Hefferon, Grealy \& Mutrie
درباره اولين مضمون كه واكنش به سانحه است، اين مطالعه

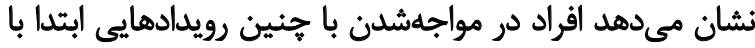

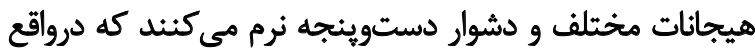

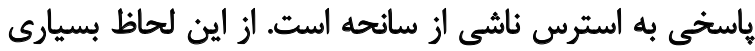

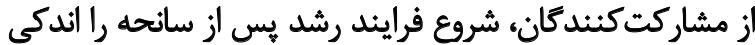

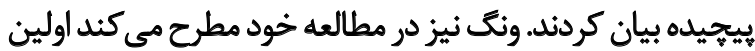

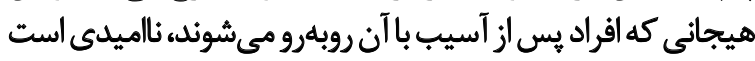

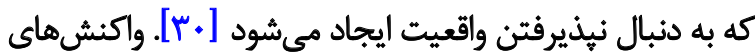

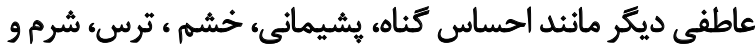

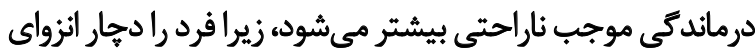

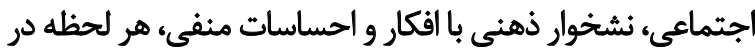

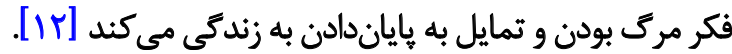
بر اساس يافتههاي اين برؤوهش، كذشت زمان و درك واقعيت

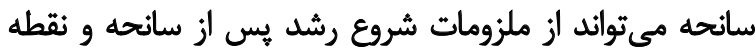

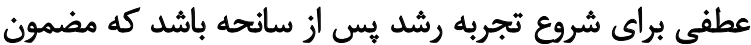

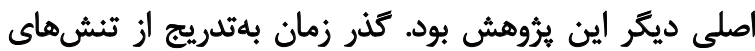

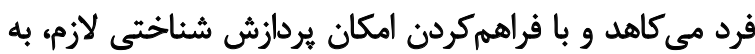

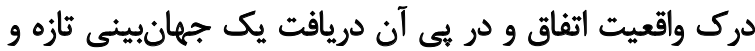

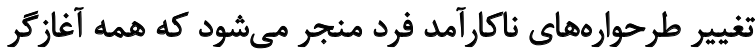

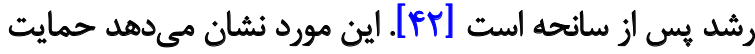

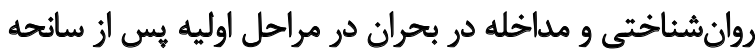

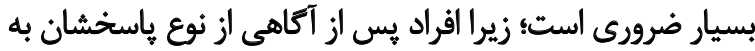

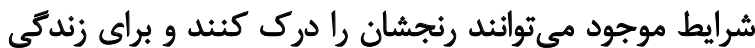

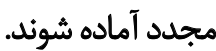

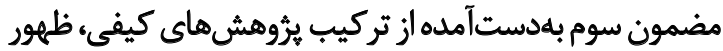

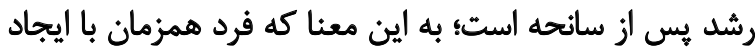

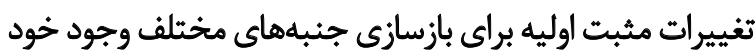

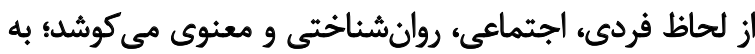

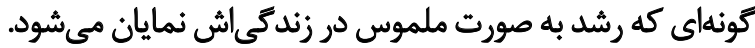

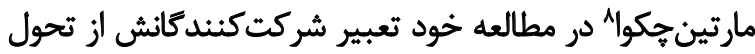

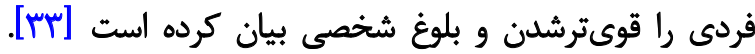

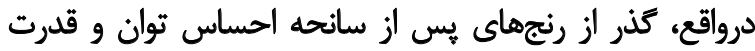

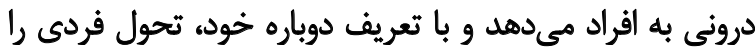

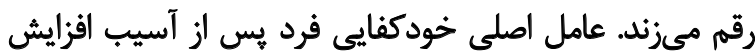

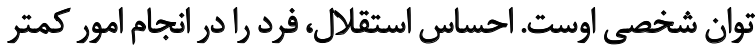

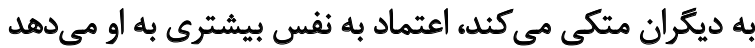

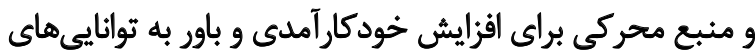

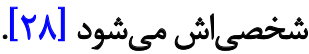

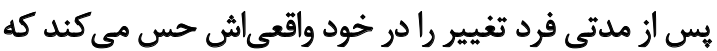

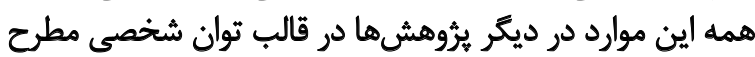

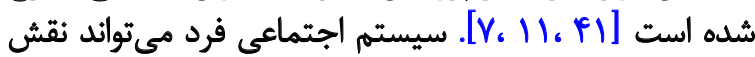

8. Martincekova 
مقالات كمى براي ياسخكويى به سؤال يُروهش به تحليل مقالات

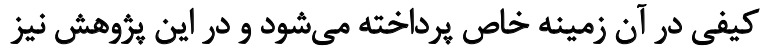

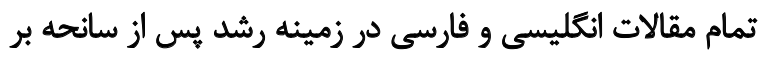

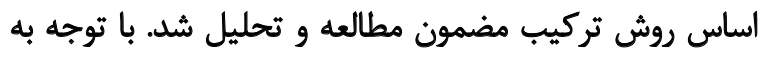

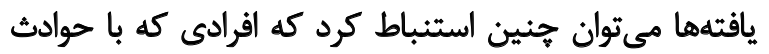

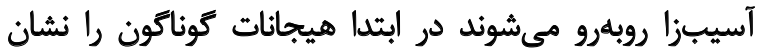

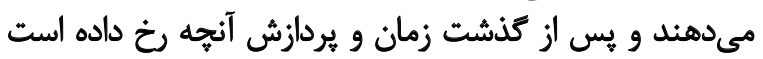

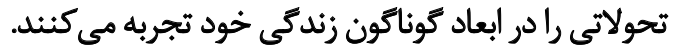

ماحظات اخلاقي - ماتى

يبروى از الصول الخلاق بثوهش

مقاله حاضر مرور يُروهش هاى كيفي بوده كه مسائل مربوط به كد اخلاق شامل آن نمي مرون يروند.

$$
\text { حامي مالبى }
$$

مقاله مستخرج از يايان نامه نيست وحمايت مالى نداشته است.

$$
\text { هشار كث نويسندكان }
$$

مفهومسازى، روششناسى، اعتبارسنجى: تمام نويسندكان؛

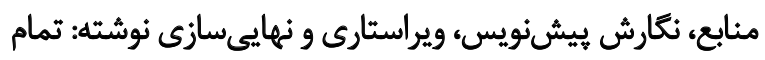

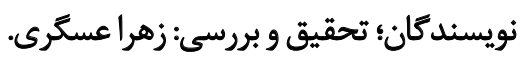

$$
\text { تعارض مناقع }
$$

بنا بر اظهار نويسندكان، اين مقاله تعارض منافع ندارد. 


\section{References}

[1] Mohamadi L, Mohamadkhani P, Dolatshahi B, Golzari M. [Posttraumatic stress disorder symptoms and their comorbidity with other disorders in eleven to sixteen years old adolescents in the city of Bam (Persian)]. Iranian Journal of Psychiatry and Clinical Psychology. 2010; 16(3):187-94.

[2] Schauer M, Schauer M, Neuner F, Elbert T. Narrative exposure therapy: A short-term treatment for traumatic stress disorders. Boston: Hogrefe Publishing; 2011.

[3] Rendon J. Upside: The new science of post-traumatic growth. New York City: Simon and Schuster; 2015.

[4] Haravuori H, Suomalainen L, Marttunen M. Quality of life in adolescents and young adults after traumatic experience. Psychiatria Fennica. 2016; 47:32-49.

[5] Ebrahimi H, Dejkam M, Seghatoleslam T. [Childhood traumas and suicide attempt in adulthood (Persian)]. Iranian Journal of Psychiatry and Clinical Psychology. 2014; 19(4):275-82.

[6] Thompson N. Crisis intervention: Dorset, England: Russell House Publishing; 2011.

[7] Karagiorgou O, Evans JJ, Cullen B. Post-traumatic growth in adult survivors of brain injury: A qualitative study of participants completing a pilot trial of brief positive psychotherapy. Disability and Rehabilitation. 2018; 40(6):655-9. [DOI:10.1080/09638288.201 6.1274337] [PMID]

[8] Tedeschi RG, Calhoun LG. The posttraumatic growth inventory: Measuring the positive legacy of trauma. Journal of Traumatic Stress. 1996; 9(3):455-71. [DOI:10.1002/jts.2490090305]

[9] Tedeschi RG, Calhoun LG. Posttraumatic growth: Conceptual foundations and empirical evidence. Psychological Inquiry. 2004; 15(1):1-18. [DOI:10.1207/s15327965pli1501_01]

[10] Calhoun L, Tedeschi R, Cann A, Hanks E. Positive outcomes following bereavement: Paths to posttraumatic growth. Psychologica Belgica. 2010; 50(1-2):125-43. [DOI:10.5334/pb-50-1-2-125]

[11] Mehrabi E, Hajian S, Simbar M, Houshyari M, Zayeri F. Posttraumatic growth: A qualitative analysis of experiences regarding positive psychological changes among Iranian women with breast cancer. Electron Physician. 2015; 7(5):123-9. [PMID] [PMCID] [DOI:10.14661/1239]

[12] Fazel M, Bagestani H, Farahbakhsh K, Esmaeili M. [Post traumatic growth Model in cancer patients: A grounded theory study (Persian)]. Counseling Culture and Psycotherapy. 2017; 8(29):79-105

[13] Abedi H, Hossenigolafshani SZ, Ahmadi F. [Reflection on the experiences of disabled people: The society as a cause of growth or barrier (Persian)]. Journal of Qualitative Research in Health Sciences. 2013; 2(3):248-60.

[14] Paredes AC, Pereira MG. Spirituality, distress and posttraumatic growth in breast cancer patients. Journal of Religion and Health. 2018; 57(5):1606-17.

[15] Gesselman AN, Bigatti SM, Garcia JR, Coe K, Cella D, Champion VL. Spirituality, emotional distress, and post-traumatic growth in breast cancer survivors and their partners: An actorpartner interdependence modelling approach. Psycho-Oncology. 2017; 26(10):1691-9. [DOI:10.1002/pon.4192] [PMID] [PMCID]
[16] Zhou X, Wu X, Zhen R. Understanding the relationship between social support and posttraumatic stress disorder/posttraumatic growth among adolescents after Ya' an earthquake: The role of emotion regulation. Psychological Trauma: Theory, Research, Practice, and Policy. 2017; 9(2):214-21. [DOI:10.1037/tra0000213] [PMID]

[17] Cao W, Qi X, Cai DA, Han X. Modeling posttraumatic growth among cancer patients: The roles of social support, appraisals, and adaptive coping. Psycho-Oncology. 2018; 27(1):208-15. [DOI:10.1002/pon.4395] [PMID]

[18] Mattson E, James L, Engdahl B. Personality factors and their impact on PTSD and post-traumatic growth is mediated by coping style among OIF/OEF veterans. Military Medicine. 2018; 183(10):481-8. [DOI:10.1093/milmed/usx201] [PMID]

[19] McDiarmid L, Taku K. Family-valued and personally important posttraumatic growth in American and Japanese adolescents. Journal of Child and Family Studies. 2017; 26(2):357-69. [DOI:10.1007/s10826-016-0565-8]

[20] Yu Y, Peng L, Chen L, Long L, He W, Li M, et al. Resilience and social support promote posttraumatic growth of women with infertility: The mediating role of positive coping. Psychiatry Research. 2014; 215(2):401-5. [DOI:10.1016/j.psychres.2013.10.032] [PMID]

[21] Yuan G, Xu W, Liu Z, An Y. Resilience, posttraumatic stress symptoms, and posttraumatic growth in Chinese adolescents after a tornado: The role of mediation through perceived social support. The Journal of Nervous and Mental Disease. 2018; 206(2):130-5. [DOI:10.1097/NMD.0000000000000778] [PMID]

[22] Kong L, Fang M, Ma T, Li G, Yang F, Meng Q, et al. Positive affect mediates the relationships between resilience, social support and posttraumatic growth of women with infertility. Psychology, Health \& Medicine. 2018; 23(6):707-16. [DOI:10.1080/13548506.20 18.1447679] [PMID]

[23] Bellur Z, Aydın A, Alpay EH. Mediating role of coping styles in personal, environmental and event related factors and posttraumatic growth relationships in women with breast cancer. Turkish Journal of Clinical Psychiatry. 2018; 21:38-51. [DOI:10.5505/ kpd.2018.65365]

[24] Rzeszutek M, Oniszczenko W, Kwiatkowska B. Stress coping strategies, spirituality, social support and posttraumatic growth in a Polish sample of rheumatoid arthritis patients. Psychology, Health \& Medicine. 2017; 22(9):1082-8. [DOI:10.1080/13548506.2 017.1280174] [PMID]

[25] Ring NA, Ritchie K, Mandava L, Jepson R. A guide to synthesising qualitative research for researchers undertaking health technology assessments and systematic reviews. Edinburgh: NHS Quality Improvement Scotland; 2011.

[26] Thomas J, Harden A. Methods for the thematic synthesis of qualitative research in systematic reviews. BMC Medical Research Methodology. 2008; 8(1):45. [DOI:10.1186/1471-2288-8-45] [PMID] [PMCID]

[27] Lincoln YS, Guba EG. Naturalistic inquiry. California: SAGE Pblication; 1985.

[28] Zhai J, Liu X, Wu J, Jiang H. What does posttraumatic growth mean to Chinese burn patients: A phenomenological study. Journal of Burn Care \& Research. 2010; 31(3):433-40. [DOI:10.1097/ BCR.0b013e3181db5240] [PMID] 
[29] Smith A, Joseph S, Das Nair R. An interpretative phenomenological analysis of posttraumatic growth in adults bereaved by suicide. Journal of Loss and Trauma. 2011; 16(5):413-30. [DOI:10 $.1080 / 15325024.2011 .572047]$

[30] Wang Y, Wang H, Wang Z, Xie H, Shi J, Zhao X. The process of posttraumatic growth in individuals with traumatic spinal cord injury in Mainland China: An interpretative phenomenological analysis. Journal of Health Psychology. 2017; 22(5):637-49. [DOI:10.1177/1359105315610812] [PMID]

[31] Hartley S, Johnco C, Hofmeyr M, Berry A. The nature of posttraumatic growth in adult survivors of child sexual abuse. Journal of Child Sexual Abuse. 2016; 25(2):201-20. [DOI:10.1080/1053871 2.2015.1119773] [PMID]

[32] Palmer E, Murphy D, Spencer-Harper L. Experience of posttraumatic growth in UK veterans with PTSD: A qualitative study. Journal of the Royal Army Medical Corps. BMJ. 2016; 0:1-6. [DOI:10.1136/jramc2015-000607]

[33] Martinčeková L, Klatt J. Mothers' grief, forgiveness, and posttraumatic grow th after the loss of achild.OMEGA-Journal of Death and Dying. 2017; 75(3):248-65. [DOI:10.1177/0030222816652803] [PMID]

[34] Zamora ER, Yi J, Akter J, Kim J, Warner EL, Kirchhoff AC. Having cancer was awful but also something good came out: Post-traumatic growth among adult survivors of pediatric and adolescent cancer. European Journal of Oncology Nursing. 2017; 28:21-7. [DOI:10.1016/j.ejon.2017.02.001] [PMID]

[35] Khanjani MS, Younesi SJ, Khankeh HR, Azkhosh M. Exploring facilitators of post-traumatic growth in patients with spinal cord injury: A qualitative study. Electronic Physician. 2017; 9(1):354453. [DOI:10.19082/3544] [PMID] [PMCID]

[36] Mapplebeck C, Joseph S, Sabin-Farrell R. An interpretative phenomenological analysis of posttraumatic growth in people with psychosis. Journal of Loss and Trauma. 2015; 20(1):34-45. [DOI:10 $.1080 / 15325024.2013 .821375]$

[37] Stein CH, Petrowski CE, Gonzales SM, Mattei GM, Majcher JH, Froemming MW, et al. A matter of life and death: Understanding continuing bonds and post-traumatic growth when young adults experience the loss of a close friend. Journal of Child and Family Studies. 2018; 27(3):725-38. [DOI:10.1007/s10826-017-0943-x]

[38] Davis CG, Wohl MJ, Verberg N. Profiles of posttraumatic growth following an unjust loss. Death Studies. 2007; 31(8):693-712. [DOI:10.1080/07481180701490578] [PMID]

[39] Chun S, Lee Y. The experience of posttraumatic growth for people with spinal cord injury. Qualitative Health Research. 2008; 18(7):877-90. [DOI:10.1177/1049732308318028] [PMID]

[40] Lee E, Kim SW, Enright RD. Beyond grief and survival: Posttraumatic growth through immediate family suicide loss in South Korea. OMEGA-Journal of Death and Dying. 2017; 30222817724700. [DOI:10.1177/0030222817724700] [PMID]

[41] Fallah R, Keshmir F, Kashani FL, Azargashb E, Akbari ME. Post-traumatic growth in breast cancer patients: A qualitative phenomenological study. Middle East Journal of Cancer. 2012; 3(2-3):35-44.

[42] Tedeschi RG. Violence transformed: Posttraumatic growth in survivors and their societies. Aggression and Violent Behavior. 1999; 4(3):319-41. [DOI:10.1016/S1359-1789(98)00005-6]
[43] Amos I. What is known about the post-traumatic growth experiences among people diagnosed with HIV/AIDS? A systematic review and thematic synthesis of the qualitative literature. Counselling Psychology Review. 2015; 30(3):47-56.

[44] Hefferon K, Grealy M, Mutrie N. Post-traumatic growth and life threatening physical illness: A systematic review of the qualitative literature. British Journal of Health Psychology. 2009; 14(2):343-78. [DOI:10.1348/135910708X332936] [PMID]

[45] Daniel T. Grief as a mystical journey: Fowler's Stages of Faith development and their relation to post-traumatic growth. Journal of Pastoral Care \& Counseling. 2017; 71(4):220-9. [DOI:10.1177/1542305017741858] [PMID] 